\title{
Primary PCI in a patient with congenitally corrected transposition of the great arteries
}

\author{
Onder Ozturk ${ }^{\mathrm{a}, *}$, Unal Ozturk ${ }^{\mathrm{b}}$, Sebnem Nergiz ${ }^{\mathrm{c}}$, Mehmet Zulkif Karahan ${ }^{\mathrm{a}}$ \\ a Diyarbakir Gazi Yasargil Education and Research Hospital, Department of Cardiology, Diyarbakir, Turkey \\ b Diyarbakir Gazi Yasargil Education and Research Hospital, Department of Neurology, Diyarbakir, Turkey \\ c Dicle University Medical Faculty, Department of Microbiology, Diyarbakir, Turkey
}

\section{A R T I C L E I N F O}

\section{Article history:}

Received 31 March 2016

Received in revised form 15 April 2016

Accepted 18 April 2016

Available online 23 April 2016

Keywords:

Congenitally corrected transposition

Myocardial infarction

Primary PCI

\begin{abstract}
A B S T R A C T
Congenitally corrected transposition of the great arteries (CCTGA) is a rare disease in which there is both ventriculoarterial and atrioventricular discordance. The systemic ventricle is of right morphology and patients are at high risk of developing systemic ventricular dysfunction. We report on a 41 year old male patient with primary $\mathrm{PCI}$ and congenitally corrected transposition of the great arteries.

(C) 2016 The Society of Cardiovascular Academy. Production and hosting by Elsevier B.V. All rights reserved. This is an open access article under the CC BY-NC-ND license (http://creativecommons.org/licenses/by-nc-nd/4.0/).
\end{abstract}

\section{Introduction}

Congenitally corrected transposition of the great arteries (CCTGA), first described by Karl von Rokitansky in 1875. CCTGA is a rare disease in which there is both ventriculoarterial and atrioventricular discordance. ${ }^{1}$ The atrioventricular discordance implies that the morphological left atrium into the morphological right ventricle (RV), and the morphological right atrium drains into the morphological left ventricle (LV). Thus, the RV supports the systemic circulation, and the LV supplies the pulmonary circulation. The systemic ventricle is of right morphology and patients are at high risk of developing systemic ventricular dysfunction. ${ }^{2}$ The clinical course is complicated by associated intracardiac defects such as ventricular septal defect, left atrioventricular valve regurgitation, subvalvar and valvar pulmonary stenosis, and atrioventricular conduction disturbances. Their life expectancy is limited by the onset of systemic (morphologically right) ventricular failure in their 40s or 50s. ${ }^{3}$

We report here the interesting case of primary PCI (Percutaneous Coronary Intervention) with congenitally corrected transposition of the great arteries.

\section{Case report}

A 41 year old male presented to the emergency department complaining of chest pain with no history of previous episodes in the 5 March 2011. His chest pain began at the rest and lasted several hours. The pain was substernal, with radiation to his back and left arm. He had

\footnotetext{
* Corresponding author. Tel.: + 905332652602.

E-mail address: droozturk21@hotmail.com (0. Ozturk).

Peer review under responsibility of The Society of Cardiovascular Academy.
}

several risk factors including smoking and dyslipidemia. On admission, he was diaphoretic and restless. His pulse was regular at 85 beats/min and his blood pressure was 110/70 mm-Hg. Physical examination showed no remarkable findings. His initial electrocardiogram (ECG) demonstrated sinus rhythm, $2 \mathrm{~mm}$ ST elevation and peaked T wave in leads V1-V3 and negative T wave in leads D1,aVL,V4-V6, incomplete LBBB (Fig. 1). We administered $100 \mathrm{IU} / \mathrm{kg}$ unfractionated heparin i.v., $300 \mathrm{mg}$ aspirin per os (chewed), $600 \mathrm{mg}$ clopidogrel per os. It was decided to perform emergency coronary angiography with primary $\mathrm{PCI}$.

The left coronary angiogram was performed. Left main was normal. LAD had got $40 \%$ stenosis after first diagonal (D1). D1 was small and had got proximal $60 \%$ stenoses. Coronary angiography showed two $\mathrm{Cx}$ arteries arising from the left main and right coronary arteries. Coronary angiography revealed that the left $\mathrm{Cx}(\mathrm{LCx})$ originating from the left main coronary artery was normal. There was another $\mathrm{Cx}(\mathrm{RCx})$ arising from the proximal part of the right coronary artery (RCA) with a significant stenosis in the mid segment. The right coronary angiogram was performed and it was shown that the RCA had got plaque (Fig. 2a-b) Primary percutaneous coronary intervention including balloon angioplasty and stenting was successfully performed for the RCx lesion (Fig. 3).

Cardiac biomarkers on admission were; CK: 83 U/L, CKMB:24 IU/L, Troponin I: $0.35 \mu \mathrm{g} / \mathrm{L}$. Cardiac biomarkers after $6 \mathrm{~h}$ on admission were; CK: $487 \mathrm{U} / \mathrm{L}, \mathrm{CKMB}: 78 \mathrm{IU} / \mathrm{L}$, Troponin I: $3.66 \mu \mathrm{g} / \mathrm{L}$. Cardiac biomarkers after 2 days on admission were CK: $857 \mathrm{U} / \mathrm{L}, \mathrm{CKMB}: 67 \mathrm{IU} / \mathrm{L}$, Troponin I: $8.5 \mu \mathrm{g} / \mathrm{L}$.

Echocardiography showed that the aorta to arise from the morphological RV, which was identified by the three leaflet tricuspid valve that inserted more proximally than the mitral valve (Fig. 4a-b). The pulmonary trunk, identified by its bifurcation, arose from the morphological LV. The systemic ventricle (RV) was normal, the walls measured $11 \mathrm{~mm}$, and the systolic RV function was normal. There was mild 


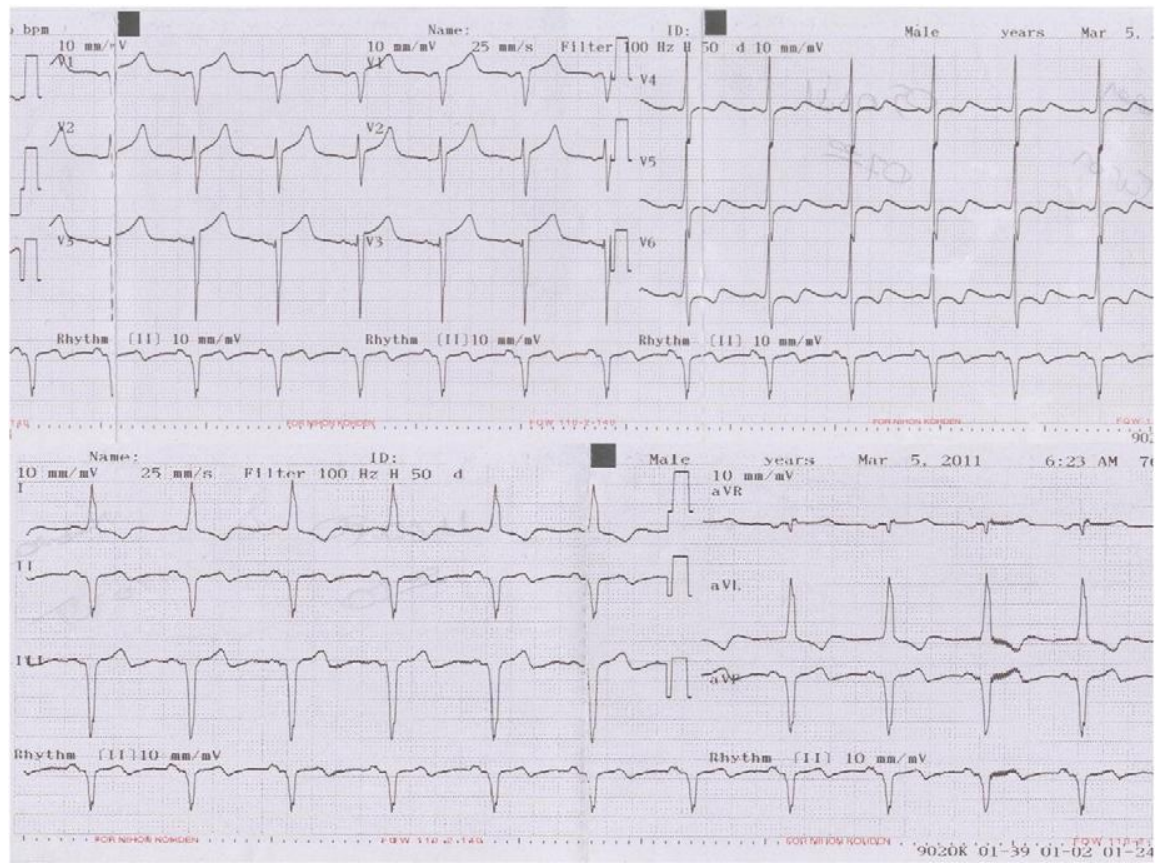

Fig. 1. Electrocardiogram of patient at admission to coronary care unit.

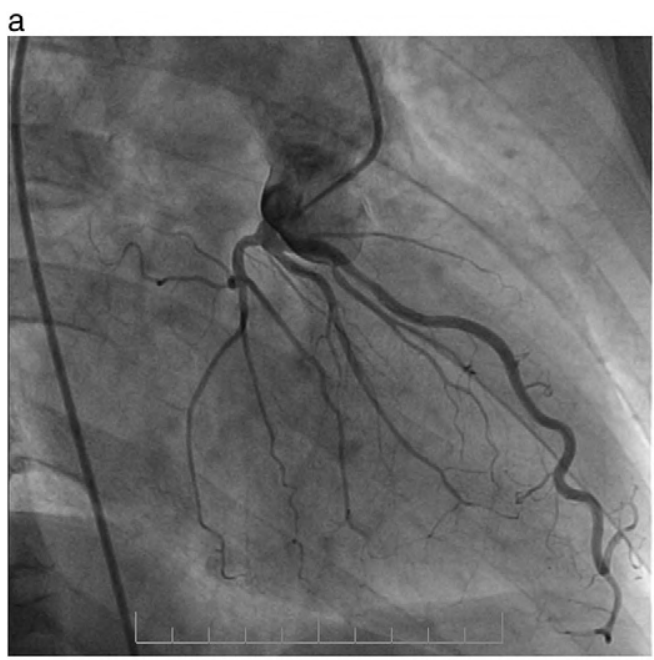

b

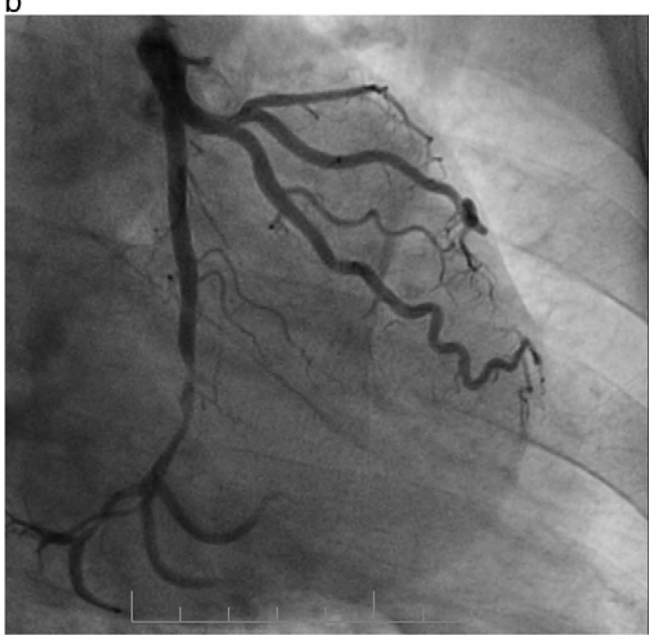

Fig. 2. a: Coronary angiograms of a patient with congenitally corrected transposition of the great arteries pre PCI. b: Coronary angiograms of a patient with congenitally corrected transposition of the great arteries pre PCI. atrioventricular (tricuspid) valve regurgitation. The pulmonic ventricle (LV) function was mildly reduced (ejection fraction 55\%). Echocardiography showed that mild hypokinesis in basal septum. There was a mild atrioventricular (mitral) valve regurgitation. There was a moderate aortic regurgitation but no pulmonary valvar stenosis. No intracardiac shunts were found. The systolic pulmonary pressure was $42 \mathrm{mmHg}$. Informed consent was obtained from the patient.

\section{Discussion}

The usual coronary arrangement in patients with congenitally corrected TGA being coronary inversion; therefore, although the morphologic right ventricle is on the left side of the heart, it is supplied by a morphologic right coronary artery system. This system may provide inadequate flow in the presence of considerable myocardial hyperplasia and hypertrophy seen when the right ventricle functions at systemic pressures for long periods. Examination of the right ventricle subjected

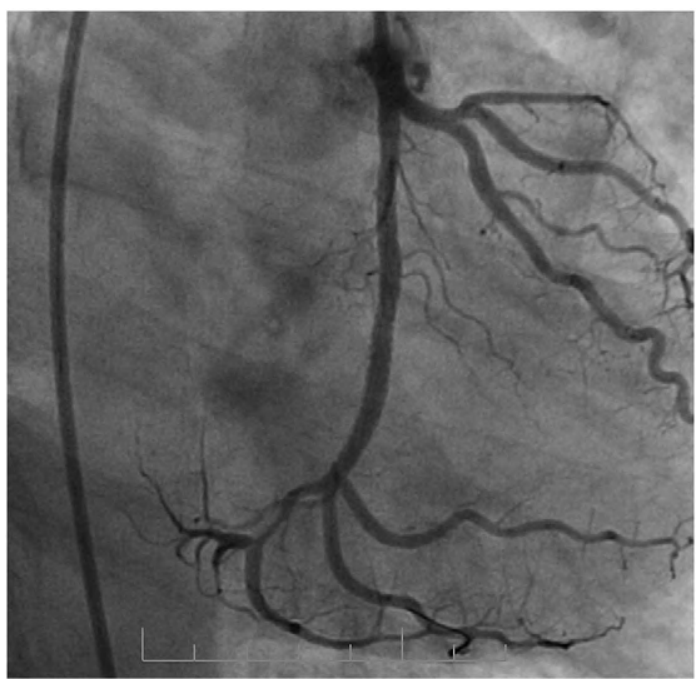

Fig. 3. Coronary angiograms of a patient with congenitally corrected transposition of the great arteries after $\mathrm{PCI}$. 

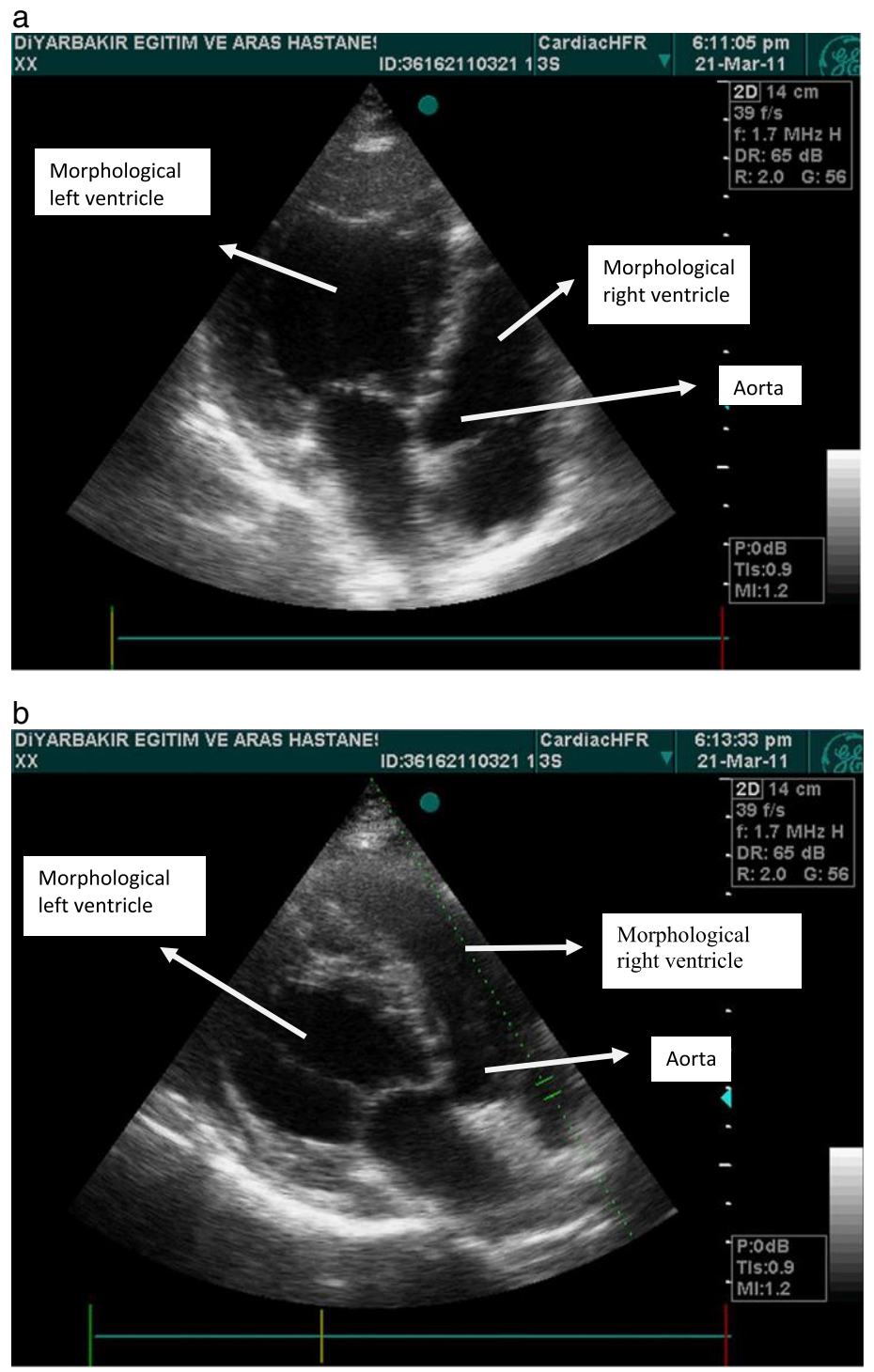

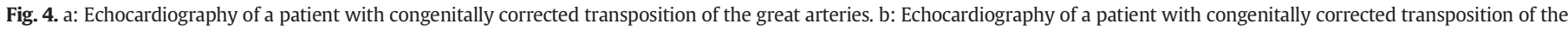
great arteries.

to systemic pressure shows gross hypertrophy compared with the thin wall of the right ventricle subjected to normal pressure, the discrepancy being especially conspicuous towards the apex. Hypertrophy places substantial extra demand on the right coronary arterial supply, which is less extensive than from a left coronary system. Progressive ischaemia will probably develop in this condition. Coronary artery anomalies in congenitally corrected transposition of the great arteries have seldom been reported in the medical literature due to the rarity of this disorder and the relatively small number of patients in each reported series. ${ }^{3}$

Patients with CCTGA rarely survive to old age. Our patient is noteworthy for several reasons. CCTGA without associated intracardiac defects is very rare. Our patient had got congenital coronary artery anomalies. In addition this case presents rarely described in the medical literature, namely, the primary PCI in patients with a CCTGA.

Much controversy exists regarding the ability of the morphological RV to support the systemic circulation. In patients with CCTGA, who present as a naturally occurring model of this adaptation, systemic ventricular failure is the cause of death in more than $50 \%{ }^{4}$ A progressive deterioration of the systolic function of the systemic ventricle has also been described in patients without associated cardiac defects. Complete heart block and increasing left (tricuspid) atrioventricular valve regurgitation are known contributing factors. ${ }^{1,4}$ However, our patient presented with a protected systemic ventricular systolic function. Causes of protected systemic ventricular function of our patient are no evidence for severe concomitant heart disease, advanced age and, hypertension.

\section{Conclusion}

This case is an example of a typical presentation of acute coronary syndrome and primary $\mathrm{PCI}$ in a patient with a congenitally corrected transposition of the great arteries.

\section{References}

1. Curzytek A, Cioch-Domarska W, Gutkowski K, Błaz W, Guz W, Lubas W. Congenitally corrected transposition of the great arteries with coexisting stenosis of pulmonary trunk valve and ventricular septum defect in a 55-year-old woman-a case report. Kardiol Pol 2007;65(8):972-976 (Aug).

2. Mah K, MK Friedberg. Congenitally corrected transposition of the great arteries: situs solitus or inversus. Circ Cardiovasc Imaging 2014;7(5):849-851 (Sep).

3. Warnes CA. Transposition of the great arteries. Circulation 2006;114(24):2699-2709 (Dec 12).

4. Al-faham Z, Jolepalem P, CYO Wong. The appearance of congenitally corrected transposition of the great arteries on myocardial perfusion imaging. J Nucl Med Technol 2015;43:68-69. 